\title{
Housing for people with special needs
}

\author{
Stella Lowry
}

There is a long tradition in Britain of providing special housing for the elderly, and more recently the needs of the physically and mentally ill have been considered too. But are people with special housing needs being identified and properly catered for? And what can doctors do to help?

\section{The elderly}

There is no magical age at which one becomes "old," and any special housing needs are never a consequence of age alone but rather of accompanying financial, mental, or physical disability. The old include some of our poorest, most vulnerable citizens - in 1986 a fifth of single pensioners lived in houses needing more than $£ 1000$ worth of urgent repairs to the external fabric. ${ }^{1}$ But there is also a growing group of affluent elderly consumers who can afford-and expect - the highest standards from their housing. As the proportion of old people in Britain rises they are becoming an increasingly influential political force and are more likely to succeed in changing public policy than many other groups with special housing needs.

Although aging is not a disease, older people are more likely to experience ill health than others and are less able to cope with the results. Old people are also particularly susceptible to any harmful effects of their housing. Housing for old people should be designed to prevent the more common problems.

\section{Temperature}

Hypothermia is probably the most widely recog-

British Medical Journal, London WC1H 9JR Stella Lowry, MB, assistant editor

BrMed f 1990; 300:321-3 nised problem of housing for the elderly. Old people are especially vulnerable because often they have reduced sensitivity to cold and impaired thermoregulation and because reduced mobility may hinder their ability to generate heat. The British Geriatrics Society

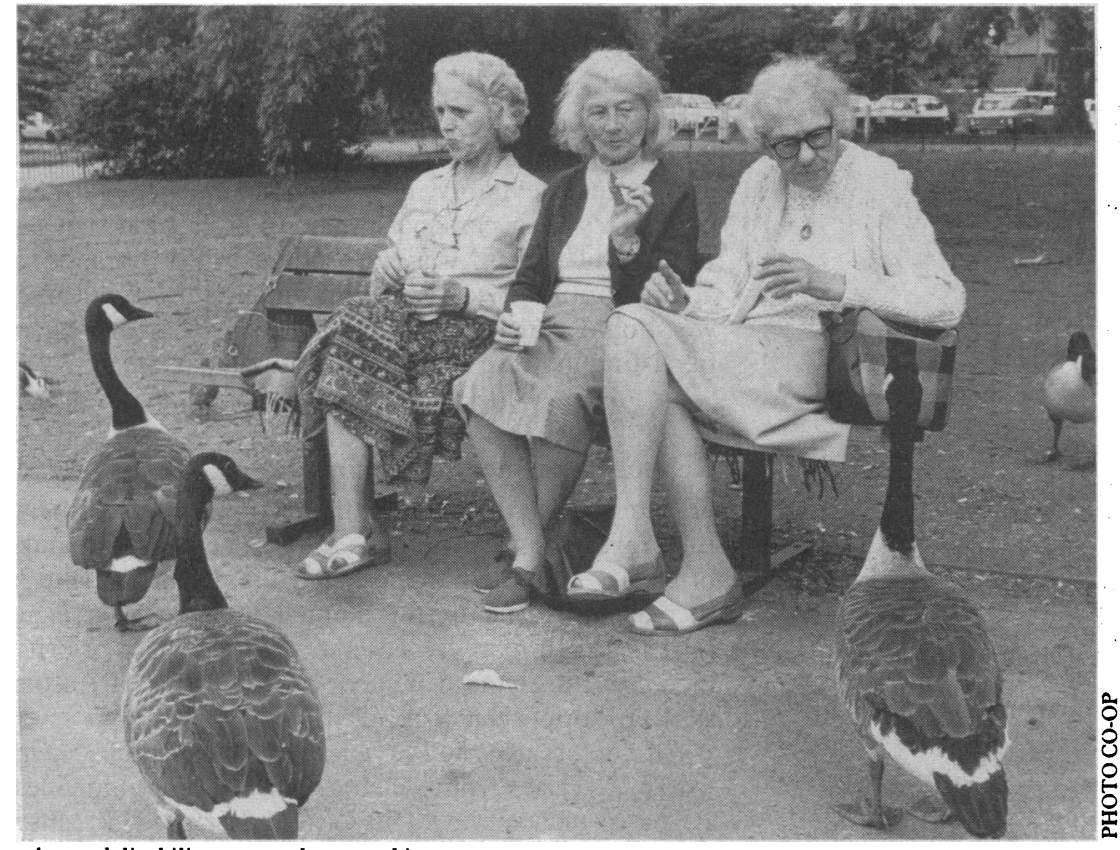

Age and disability are not the same thing advises old people to maintain their living rooms at $21^{\circ} \mathrm{C}$, but in a national survey about half the old people had a living room temperature below $16^{\circ} \mathrm{C}$, and a third had bedrooms colder than $10^{\circ} \mathrm{C} .{ }^{2}$

Many old people cannot afford to heat their homes adequately. In one survey over half the respondents mentioned that they worried about the cost of heating, and a quarter said that this sometimes deterred them from using as much heat as they would like. ${ }^{3}$ Central heating is probably the best way of heating an old person's home as it is usually the most economical system, is safer and more convenient than open fires, provides warmth throughout the house (so increasing comfort and helping to maintain the fabric by discouraging condensation), and is less dependent on the old person remembering to switch it on. It is, however, expensive to install. Occasional payments in response to very severe weather are not enough to protect old people from the effects of cold. All people, including the old, should be able to keep their houses at a safe temperature without spending more than $10 \%$ of their available income. ${ }^{4}$ Many elderly people live in old, poorly maintained houses that are especially hard to heat, and they need help with repairs and insulation as well as with fuel bills.

\section{Safety}

Home safety is especially important for elderly people because poor eyesight, restricted mobility, and deteriorating memory increase the risk of accidents; and isolation may delay the arrival of help.

In Britain people aged over 65 have about three million falls each year. ${ }^{5}$ Falls are a common reason for admitting old people to hospital, and relatives often pressurise them to move house because of the risk of a further fall. One study of elderly people applying for admission to residential care found that relatives placed far more importance on the risk of falls than did the old people themselves. ${ }^{6}$ Studies of falls in elderly people have identified many risk factors including undetected eye and foot disorders, postural hypotension, sudden changes in light intensity, loose rugs, and even poor balance in flat shoes after a lifetime of wearing high heels. ${ }^{57}$ If old people cannot get up after a fall there should be some sort of alarm system for calling help, which might be nothing more elaborate than a missed regular telephone call to a relative.

In recent years there has been an increase in the amount of violent crime against old people in their homes. Health workers are partly to blame for the vulnerability of old people to such attacks. We expect elderly people to leave their front doors open so that we can gain access easily, and few of us offer any identification. Attitudes like these make old people too willing to trust visitors to their homes.

\section{Choice is important}

Some houses are more easily adapted for old people than others. Stairs present an obvious hazard, but badly designed bathrooms and kitchens also pose problems for people with restricted movement or poor balance. ${ }^{89}$ The Centre for Applied Gerontology at the University of Birmingham conducts consumer tests of 
products designed for elderly people, and its recommendations include hanging kitchen units on brackets like those used for shelving systems so that an entire kitchen can be adapted quickly for wheelchair use, positioning electricity sockets at waist height and fitting plugs with handles, making all doorways wide enough for wheelchair access, installing lever taps, and providing a separate shower as well as a bath. Occupational therapists can provide aids to help old people to cope at home; but if the house is well designed to start with this task is made much easier.

Despite all that can be done to make homes safer and more comfortable many old people decide to move to specialist housing for the elderly. There are now more options than ever before, ranging from nursing homes and traditional sheltered flats to new continuing care communities. These schemes, which have become very popular in the United States, provide a range of specially designed accommodation on a single site. Old people buy into the scheme and are guaranteed accommodation for life. These complexes are marketed as providing non-institutional, high quality care for the discerning elderly consumer, but in the United States some schemes are now facing problems as the fit people who bought in some years ago are becoming more dependent.

Many old people pay no attention to their housing needs until a sudden illness leaves them unable to cope. Hasty decisions are then forced on them at a time of crisis. Few old people realise the financial implications of moving into specialist housing. Many assume that having sold their own home to gain a residential place they then have tenure for life. It is a bitter blow to find that a further deterioration in health can force them to move again when they have no resources and so no bargaining power over what happens to them. Doctors could do more to explain the implications of normal aging and present housing policy to their elderly patients so that more of them can choose where and how they live.

\section{Housing for the disabled}

Disabled people also need a choice of accommodation but have even less choice available to them than the elderly. I have already suggested that elderly people need special provision only if they are in some way disadvantaged, but at least when they do need specialist housing there is a long tradition of catering

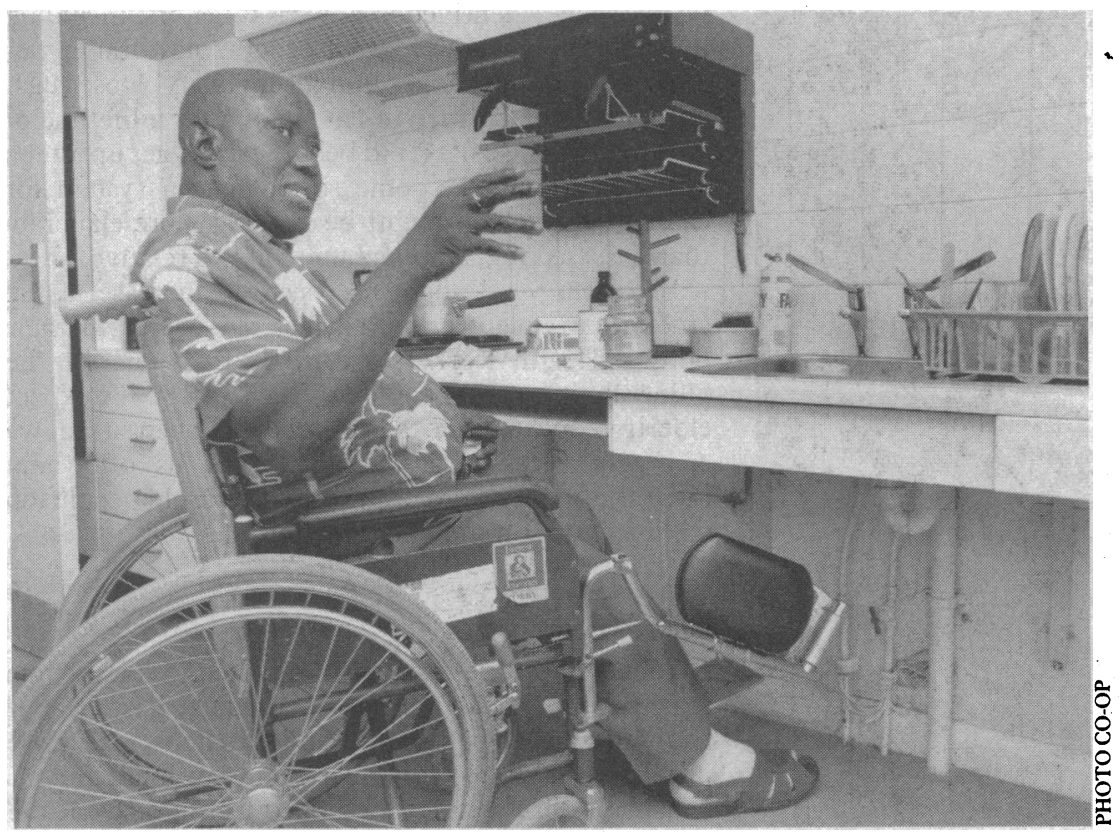

There is a shortage of suitable accommodation for young disabled people for their needs, and so a reasonable amount of choice. There is very little suitable accommodation for younger people with mental and physical disabilities, and the recent emphasis on community care has had little impact on the provision of services.

Over 400000 people aged 16-65 in Britain have a severe physical disability, and about three quarters of them live in the community, depending largely on informal carers for their basic needs. ${ }^{10}$ It is now government policy to close many long stay mental hospitals, and the displaced patients are also seeking homes in the community. More and more disabled people are now living in the community, and if they are not given appropriate support their homes can become one of their greatest handicaps.

The challenge in community care is to provide appropriate supporting services without stigmatising the recipients. Using trendy terms like "clients" instead of "patients" is not enough. It is often simpler and cheaper to provide a package of services on a single site, and many community care schemes are effectively small ghettos of handicapped people. Placing all specialist housing in a small area may make services easy to deliver, but it also makes the residents stand out from the rest of the community.

There are a few good housing schemes for physically and mentally disabled people, ${ }^{10} 11$ but as always it is the articulate people or those with good advocates who get the best services, and there is a tremendous inequality of provision, with multiply handicapped people and those from ethnic minorities often missing out. More than three quarters of a million physically handicapped people in Britain are inadequately housed, and the National Federation of Housing Associations estimates that there is a shortage of at least 150000 purpose built or suitably adapted houses in the public sector. Present housing law adds to the problems. Legislation giving council tenants the right to buy their houses at large discounts has deprived many councils of some of their best housing, including many of the most easily adapted homes. The community charge may discourage people from caring for handicapped relatives at home; although some handicapped people will be exempt, the situation is still very confused. Present rules on homelessness mean that local authorities are not responsible for housing people who are voluntarily homeless, even if this is the result of them leaving their accommodation during an exacerbation of a mental illness. ${ }^{12}$

Ideally, community care should provide handicapped people with the rights that the rest of us take for granted. They should be able to choose where and with whom they live, who may enter their home, their furnishings and decorations, what time they get up or go to bed, what they eat, when and where they shop, and so on. Inevitably, however, dependence on other people restricts personal freedom. It is time that an element of realism was reintroduced into discussions about community care-compromise is inevitable and we should concentrate on minimising it rather than persisting in futile attempts to eliminate it.

\section{Rehousing on medical grounds}

The poor state of much of Britain's housing stock, the grave shortage of homes to rent, and the demands of groups like the homeless and the disabled make it increasingly difficult for council tenants to arrange rehousing. In many places a medical claim to priority increases the chances of success, and doctors are often asked to support such applications.

All doctors need to know how the rehousing system works. It varies from place to place; these guidelines are based on a survey of 55 local authorities. ${ }^{13}$ Because there are too few houses to go round, new applicants 


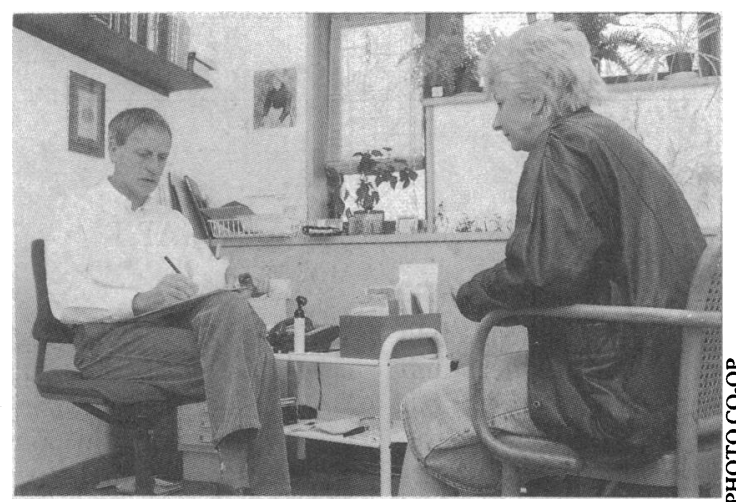

Doctors are often asked to support applications for rehousing

for council property and existing tenants requesting a transfer usually face a long wait. Local authorities often try to give priority to applicants on the basis of the time spent on the list or by allocating "points" for factors such as family size, overcrowding, standards of present accommodation, and relevant medical problems.

The survey found that authorities use one or another of four ways of collecting medical information: self reporting, information from general practitioners, information collected by specially trained visitors, and assessment by a housing officer. Once collected, the information is reviewed by a medical assessor, usually a community physician, who advises about whether priority should be awarded.

General practitioners need to be familiar with their local system. They need to know whether information should be provided on a special form and to whom it should be addressed. This avoids repeated requests for more information. Doctors should also remember that it is the degree of disability, not the specific diagnosis, that matters. Emphasis on diagnoses may even be unhelpful-if council employees screen applications they are unlikely to appreciate that "nervous diseases" mean conditions like multiple sclerosis and Parkinson's disease rather than depression.

\section{Medical priority can be unfair}

It is difficult to prove that rehousing has much impact on health. A follow up study in Bolton found that nearly a quarter of people rehoused on medical grounds three years earlier thought that their health had improved as a result, but just over a tenth were still unhappy. ${ }^{14}$ Studies of people in Salford applying for rehousing on the grounds of mental ill health found that they improved after rehousing, ${ }^{1516}$ but there are many biases in such studies. It is impossible for subjects to be blinded to the treatment (rehousing), and because many people may exaggerate their symptoms to gain priority any improvement observed after rehousing may be an artefact.

Medical priority for rehousing can be unfair. One of the studies in Salford found that many of the control group also had neurotic symptoms. ${ }^{16}$ The authors concluded that a priority system reduces the chances of rehousing for those who do not make a special claim, regardless of their genuine problems. Once again, it is the articulate and aggressive who gain most.

A medical claim for priority is no guarantee of success. Gray found that less than a twentieth of applications for rehousing on medical grounds were successful. ${ }^{17}$ Dr Luise Parsons, acting district medical officer in the Northern region, thinks that the scheme is merely a way of deflecting blame for failure to rehouse away from the local authority. "The bottom line is that we haven't got enough houses."

Doctors are placed in a difficult position when asked for support. It is hard to refuse to try to help a patient, even when you know that your list contains many more deserving cases. Many doctors supply reports for all who request them and salve their consciences with the knowledge that the housing shortage is so great that they are unlikely to have any effect anyway. Others devise schemes to support only the most needy cases without offending anyone: a recent conference heard how one housing authority ignored all of the written requests from a particular doctor unless he also telephoned.

\section{Conclusions and comment}

Many people have special housing needs because they are poor or ill or disabled. Schemes that target help at older age groups, without specifying disability, often waste resources that could be better used by younger people. The ideals of community care for the physically handicapped and mentally ill hinge on the provision of good housing. There are not enough specially adapted homes to cater for the needs of disabled people, and there are too few well maintained houses in the public sector to provide healthy housing for other "special" groups such as families, the poor, the homeless, and the unemployed. There are not enough good houses to go round, and it does not require a medical degree to spot the most needy cases, such as bilateral amputees living in tower blocks. Perhaps doctors should distance themselves from the shambles of prioritising cases and campaign instead for improved standards for all.

1 Department of the Environment. English house condition survey 1986. London HMSO, 1988

Wicks M. Old and cold. Hypothermia and social policy. London: Heinemann, 1978

3 Savage AV. Warmth in winter: evaluation of an information pack for elderly people. Cardiff: University of Wales College of Medicine Research Team for the Care of the Elderly, 1988.

4 Lowry S. Temperature and humidity. Br Med f 1989;299:1326-8.

5 Gabell A, Simons MA, Nayak USL. Falls in the healthy elderly: predisposin

causes. Ergonomics 1985;28:965-75.
6 Neill J. Assessing elderly people for residential care: a practical guide. London National Institute for Social Work Research Unit, 1989.

National Institute for Social Work Research Unit, 1989.

8 Civesley B. Falls in older age. Br Med f 1984;289:568-9. Cof

of Birmingham, 1988.

Centre for Applied Gerontology. The better bathroom. Birmingham: University of Birmingham, 1988.

10 Fiedler B. Living options lottery. Housing and support services for people with severe physical disabilities, 1986/88. London: The Prince of Wales's Advisory Group on Disability, 1988.

1 Wertheimer A. Housing: the foundation of community care. London: National Federation of Housing Associations, 1989.

2 Lowry S. Concern for discharged mentally ill patients. Br Med f 1989;298: 209-10.

13 Parsons L. Medical priority for rehousing. Public Health 1987;101:435-41.

14 Cole D, Farries JS. Rehousing on medical grounds-assessment of its effectiveness. Public Health 1986;100:229-35.

15 Elton PJ, Packer JM. A prospective randomised trial of the value of rehousing on the grounds of mental ill health. F Chronic Dis 1986;39:221-7.

16 Elton PJ, Packer JM. Neurotic illness as grounds for medical priority for rehousing. Public Health 1987;101:233-42.

17 Gray JAM. Housing, health, and illness. Br Med f 1978;ii:100-1

\section{Correction}

\section{Housing and health: Accidents at home}

An author's error occurred in this article by Stella Lowry (13 January, p 104). The cost of domestic accidents to the health service in England and Wales is about $£ 300$ million a year, not $£ 300000$ as published. 